\title{
Comparison Between Subjective Examination (Trial And Error) And Objective Examination (Streak Retinoscopy) In Children With Myopia At The Ar-Raudhatul Hasanah Islamic Boarding School Medan \\ Farid Alfarisy ${ }^{\mathrm{a},}$ Aryani A Amra ${ }^{\mathrm{b}}$,Fithria Aldy ${ }^{\mathrm{c}}$
}

\begin{abstract}
Background : Refractive errors are also the most common cause of vision impairments.

Aim: To assess the comparison of the results of the corrective examination in a subjective way using Trial and Error in an objective way with streak retinoscope examination in students at the Ar-Raudhatul Hasanah Islamic Boarding School.
\end{abstract}

Method : This study is an analytic observational with a cross sectional data collection method, the sample of this study is students at the Ar-Raudhatul Hasanah Islamic boarding school who diagnosed myopia with age $11-\leq 18$ years old.

Result : In 57 subjects study, age data were obtained between $11-\leq 18$ years, with average 14.1 years, with 42 male subjects $(73.7 \%)$ and 15 women (26.3\%). From this study, it can be seen that the data on the way of examination subjectively and objectively to the right eye can be done by means of a diagnostic test, where the sensitivity value of the subjective and objective examination correction results in the right eye is $82.7 \%$. The specificity of the results of subjective and objective examination correction in the right eye was $20.0 \%$. The positive predictive value of subjective and objective examination correction results in the right eye is $91.5 \%$. The negative predictive value of the subjective examination correction results is not accurate and the objective correction results in the right eye is exactly $20.0 \%$ and the accuracy in the subjective and objective examination in the right eye is $77.0 \%$ where the sensitivity value of the correction results between subjective and objective examination of the left eye with a value of $98.0 \%$. The specificity of the correction results is $25.0 \%$. Positive predictive value $88.9 \%$. The negative predictive value is $66.4 \%$ and the value level is $87.7 \%$.

Conclusion : In this study, data was obtained that the level of sensitivity, specificity, positive predictive value, negative predictive value and examination accuracy in each examination method had different values.

Keyword: Trial and error, streak retinoscope 


\section{Introduction}

A refractive error, also called ametropia, is a state of refraction in which parallel rays that come from an infinite distance into the eye are not precisely refracted on the retina without any accommodation (Ferris, 2017). In Indonesia, refractive errors are also the most common cause of vision impairments. Based on the results of rapid assessment of avoidable Blindness or RABB 2014-2016 survey in 15 provinces, it showed that the main cause of visual impairments and blindness is $10-15 \%$ refractive errors. According to the data that taken from basic health study (Riskesdas) in 2013, it shows the use of glasses or contact lenses for distant viewing by province in North Sumatra $4.0 \%$, while severe low vision $0.9 \%$. And there is also a prevalence in high school students who wear glasses or contact lenses $7.0 \%$, while severe low vision is $0.3 \%$ (Siregar, 2008). Some studies stated that myopia is influenced by heredity factors (genetic) and the habit of using visual organ (environment) namely near-work activities, such as reading and playing games that often occur among students. Nowadays, digital technology is growing rapidly where almost all of them use screens with HD (High Definition) quality exposure. So that healthy reading techniques (reading position, reading distance, reading time and lighting) are needed to prevent early myopia (Lang, 2000)

According to WHO in the Global Data on Visual Impairments 2010, it is stated that 285 million people world have visual impairment with the most common cause is unresolved refractive errors by $43 \%$ and the cause of blindness as much as $3 \%$ (Tien, 2001)

The examination for refractive errors correction can be carried out by subjective and objective examination. Subjective Refraction Examination is an eye examination (refraction) where there is cooperation between examiner and patients. Subjective refraction examination can be done using trial and error examination (Hashim, 2012).

Objective Refraction Examination is an eye examination (refractive) in which the patient is passive, the measurement results are obtained by the observation of an instrument. Objective Refraction Examination with autorefractometer is mostly done in Optics, Eye Clinic and Hospital. In addition to the autorefractometer, it can also be checked with Streak Retinoscopy (Fricke, 2012)

The comparison between autorefractor and subjective refraction examination shows the mean spherical equivalent value, autorefractor assessment shows more negative values than the subjective examination results. Comparison of retinoscopy examination results with subjective refraction examinations showed insignificant statistical differences. (Zamillah 2014 \& Sherwin, 2012)

\section{Participants and Methods}

This study is analytic descriptive study with a cross sectional measurement methods by taking data at Ar- Raudhatul Hasanah Islamic Boarding School. The study population that obtained from at Ar- Raudhatul Hasanah Islamic Boarding School students who met the inclusion criteria (students who diagnosed myopia with age $11-\leq 18$ years old) and exclusion criteria (students who diagnosed astigmatism, hypermetropia, ambliopia, anterior segment abnormalities, congenital abnormalities, or have a history of eye surgery). The sample size is determined by the Total Sampling method, namely all Ar- Raudhatul Hasanah Islamic Boarding School students with myopia (57people).

\section{Results and Discussion}

The study was conducted by first recording the identity of patients who met the sample selection criteria, secondly, performing visual acuity test with a Snellen Chart, then correcting refraction in patients with decreased visual acuity using a subjective refractive examination (trial and error), and lastly, performed refraction correction with objective refraction 
examination (streak retinoscopy), then diagnosed myopia in 57 samples. After processing the data, the following results are obtained:

Tabel 1. Patient Demographics

\begin{tabular}{|c|c|c|}
\hline & $N$ & $\%$ \\
\hline \multicolumn{3}{|l|}{ Gender } \\
\hline - Male & 42 & 73.7 \\
\hline - Female & 15 & 26.3 \\
\hline Total & 57 & 100,0 \\
\hline
\end{tabular}

Table 2. Initial Visual acuity in the Ocular Dextra (OD) and Sinistra (OS)

\begin{tabular}{ccccc}
\hline \multirow{2}{*}{ Visual acuity } & \multicolumn{1}{c}{ OD } & \% & $\boldsymbol{N}$ & OS \\
\cline { 2 - 5 } & $\boldsymbol{N}$ & 1.8 & 1 & $\mathbf{\%}$ \\
\hline $6 / 8$ & 1 & 15.8 & 9 & 1.8 \\
$6 / 9$ & 9 & 5.3 & 1 & 15.8 \\
$6 / 12$ & 3 & 5.3 & 6 & 1.8 \\
$6 / 18$ & 3 & 8.8 & 4 & 10.5 \\
$6 / 24$ & 5 & 31.6 & 14 & 7.0 \\
$6 / 36$ & 18 & 7.0 & 6 & 24.6 \\
$6 / 60$ & 4 & 12.3 & 9 & 3.5 \\
$5 / 60$ & 7 & 3.5 & 1 & 5.3 \\
$4 / 60$ & 2 & 5.3 & 3 & 1.8 \\
$3 / 60$ & 3 & 3.5 & 2 & 15.8 \\
$1 / 60$ & 2 & $\mathbf{1 0 0 . 0}$ & $\mathbf{5 7}$ & $\mathbf{1 0 0 . 0}$ \\
\hline Total & $\mathbf{5 7}$ & & & \\
\hline
\end{tabular}

Table 3. Subjective Spherical Lens in the OD and the OS

\begin{tabular}{|c|c|c|c|c|}
\hline \multirow{2}{*}{ Lens } & \multicolumn{2}{|c|}{ OD } & \multicolumn{2}{|c|}{ OS } \\
\hline & $N$ & $\%$ & $N$ & $\%$ \\
\hline 0 & 0 & 0 & 1 & 1.8 \\
\hline$-0,25$ & 10 & 17.5 & 9 & 15.8 \\
\hline$-0,5$ & 3 & 5.3 & 5 & 8.8 \\
\hline$-0,75$ & 3 & 5.3 & 1 & 1.8 \\
\hline$-1,00$ & 1 & 1.8 & 4 & 7.0 \\
\hline$-1,25$ & 2 & 3.5 & 3 & 5.3 \\
\hline$-1,5$ & 13 & 22.8 & 5 & 8.8 \\
\hline$-1,75$ & 6 & 10.5 & 5 & 8.8 \\
\hline-2 & 2 & 3.5 & 4 & 7.0 \\
\hline$-2,25$ & 4 & 7.0 & 8 & 14.0 \\
\hline$-2,5$ & 6 & 10.5 & 5 & 8.8 \\
\hline$-2,75$ & 1 & 1.8 & 1 & 1.8 \\
\hline$-3,50$ & 1 & 1.8 & 1 & 1.8 \\
\hline$-5,00$ & 2 & 3.5 & 2 & 3.5 \\
\hline$-5,25$ & 1 & 1.8 & 1 & 1.8 \\
\hline$-5,50$ & 2 & 3.5 & 2 & 3.5 \\
\hline Total & 57 & 100.0 & 57 & 100.0 \\
\hline
\end{tabular}


Table 4. Subjective Correction Results in the OD and the OS

\begin{tabular}{|c|c|c|c|c|}
\hline \multirow{2}{*}{ Result } & \multicolumn{2}{|c|}{ OD } & \multicolumn{2}{|c|}{ OS } \\
\hline & $\mathbf{N}$ & $\%$ & $\mathbf{N}$ & $\%$ \\
\hline Correct & 47 & 82,5 & 54 & 94,7 \\
\hline Incorrect & 10 & 17,5 & 3 & 5,3 \\
\hline Total & 57 & 100,0 & 57 & 100,0 \\
\hline
\end{tabular}

Table 5. Streak Retinoscopy in the OD and the OS

\begin{tabular}{ccccc}
\hline \multirow{2}{*}{ Lens } & OD & \multicolumn{3}{c}{ OS } \\
\cline { 2 - 5 } & $\mathbf{N}$ & $\mathbf{\%}$ & $\mathbf{N}$ & $\mathbf{\%}$ \\
\hline$-5,75$ & 0 & 0 & 1 & 1.8 \\
$-5,25$ & 1 & 1.8 & 0 & 0 \\
$-5,00$ & 1 & 1.8 & 2 & 3.5 \\
$-4,75$ & 2 & 3.5 & 0 & 0 \\
$-4,25$ & 1 & 1.8 & 1 & 1.8 \\
-4.00 & 0 & 0 & 1 & 1.8 \\
-3.50 & 0 & 0 & 1 & 0.8 \\
$-3,00$ & 1 & 1.8 & 0 & 1.8 \\
2.75 & 0 & 0 & 1 & 8.8 \\
$-2,50$ & 5 & 8.8 & 5 & 8.8 \\
$-2,25$ & 1 & 1.8 & 5 & 12.2 \\
$-2,00$ & 8 & 14.0 & 7 & 3.5 \\
$-1,75$ & 8 & 14.0 & 2 & 12.2 \\
$-1,50$ & 9 & 15.8 & 7 & 8.8 \\
$-1,25$ & 3 & 5.3 & 5 & 5.3 \\
$-1,00$ & 1 & 1.8 & 3 & 1.8 \\
$-0,75$ & 2 & 3.5 & 1 & 14.0 \\
$-0,50$ & 6 & 10.5 & 6 & 1.8 \\
$-0,25$ & 8 & 14.0 & 8 & $\mathbf{1 0 0 . 0}$ \\
0 & 0 & 0 & 1 & $\mathbf{5 7}$ \\
\hline Total & 5 & $\mathbf{1 0 0 . 0}$ & & \\
\hline
\end{tabular}

Table 6. Objective Correction Result in the OD and the OS

\begin{tabular}{lccccc}
\hline \multirow{2}{*}{ Result } & \multicolumn{3}{c}{ OD } & n & OS \\
\cline { 2 - 6 } & $\mathbf{N}$ & 91.2 & 49 & 86.0 \\
\hline Correct & 52 & 8.8 & 8 & $14 . .0$ \\
Incorrect & 5 & 100.0 & $\mathbf{5 7}$ & $\mathbf{1 0 0 . 0}$ \\
\hline Total & 57 & &
\end{tabular}

Table 7. BCVA Descriptive

\begin{tabular}{lcc}
\hline BCVA & N & \% \\
\hline BCVA (subjective) & 10 & 17.5 \\
BCVA (Objective) & 3 & 5.3 \\
BCVA (Subjective=Objective) & 44 & 77.2 \\
\hline Total & $\mathbf{5 7}$ & $\mathbf{1 0 0 . 0}$ \\
\hline
\end{tabular}

Table 8. Age Distribution

\begin{tabular}{cccccc}
\hline & n & Mean & SD & Minimum & Maximum \\
\hline Age & 57 & 14.11 & 1.749 & 11 & 17 \\
\hline
\end{tabular}


Table 9. Comparison of the Correction Results of Sub OD with Streak Retinoscopy OD

\begin{tabular}{lccc}
\hline Spherical Lens: & \multicolumn{3}{c}{ Streak Retinoscopy OD Correction Result } \\
\cline { 2 - 4 } Result of the OD & Correct & Incorrect & Total \\
\cline { 2 - 4 } Correction & $\mathbf{N}$ & $\mathbf{N}$ & $\mathbf{N}$ \\
\hline Correct & 43 & 4 & 47 \\
Incorrect & 9 & 1 & 10 \\
\hline TOTAL & $\mathbf{5 2}$ & $\mathbf{5}$ & $\mathbf{5 7}$ \\
\hline
\end{tabular}

Diagnostic Test Results :

Sensitifity

$=(43 / 52) \times 100 \%=82.7 \%$

Spesifisity

PPV

NPV

Accuracy

$$
\begin{aligned}
& =(1 / 5) \times 100 \%=20.0 \% \\
& =(43 / 47) \times 100 \%=91.5 \% \\
& =(1 / 5) \times 100 \%=20.0 \% \\
& =((43+1) / 57) \times 100 \%=77.0 \%
\end{aligned}
$$

Table 10. Comparison of the Correction Results of Sub OS with Streak Retinoscopy OD

\begin{tabular}{lccc}
\hline Spherical Lens: & \multicolumn{3}{c}{ Streak Retinoscopy OS Correction Result } \\
\cline { 2 - 4 } Result of the OS & Correct & Incorrect & Total \\
\cline { 2 - 4 } Correction & $\mathbf{N}$ & $\mathbf{N}$ & $\mathbf{N}$ \\
\hline Correct & 48 & 6 & 54 \\
Incorrect & 1 & 2 & 3 \\
\hline TOTAL & $\mathbf{5 2}$ & $\mathbf{5}$ & $\mathbf{5 7}$ \\
\hline
\end{tabular}

Diagnostic Test Results :

Sensitivity

$$
=(48 / 49) \times 100 \%=98.0 \%
$$

Specificity

$$
=(2 / 8) \times 100 \%=25.0 \%
$$

PPV

$$
=(48 / 54) \times 100 \%=88.9 \%
$$

NPV

$$
=(2 / 3) \times 100 \%=66.4 \%
$$

Accuracy

$$
=((48+2) / 57) \times 100 \%=87.7 \%
$$

\section{Discussion}

In table 1, it is explained that the most gender in this study was male, which is 42 people. In table 2 it shows the most common initial visual acuity in the study subjects was $6 / 36(31.6 \%)$ as many as 18 subjects for OD, and the most common visual acuity in the study was 6/36 (24.6\%) where was 14 subjects for OS. While, the least visual acuity was $6 / 8$ where the subjects $1(1.8 \%)$ for OD and OS.

In table 3, it shows that the most common use of subjective spherical lenses OD was $1.50 \mathrm{D}$ as many as 13 subjects $(22.8 \%)$, while the most common subjective spherical lenses OS was $-0.25 \mathrm{D}$ as many as 9 subjects (15.8\%). The lowest spherical lens strength (-) in the study was $-0.25 \mathrm{D}$ for OD and $-0.00 \mathrm{D}$ for OS, and the highest spherical lens strength was $-5.50 \mathrm{D}$ for OD and OS.

In table 4, it shows that the use of spherical lens (-) has the correct subjective correction results as many as 47 subjects $(82.5 \%)$ for OD and 54 subjects $(94.7 \%)$ for the OS.

In table 5, it shows that the most spherical lens use was $-1.50 \mathrm{D}$ as many as 9 subjects (15.8\%) for OD, and $-0.25 \mathrm{D}$ as many as 8 subjects (14\%) for OS. The lowest spherical lens 
strength in this study was $-0.25 \mathrm{D}$ for OD and $-0.00 \mathrm{D}$ for OS. While the highest spherical lens strength was $-5.25 \mathrm{D}$ lens for OD and $-5.75 \mathrm{D}$ for OS.

In table 6 , it shows that the corrections results obtained on the objective examination with streak retinoscopy as many as 52 subjects (91.2\%) for OD and 49 subjects (86\%) for the OS.

In table 7, it shows that BCVA was obtained on examination both subjectively and objectively as many as 44 subjects (77.2\%), where objective BCVA is the same as subjective BCVA.

In table 8, it shows that the age of the study subjects was 11-17 years.

In this study, correction of refractive error was done using subjective and objective examination. It can be seen in table 9 that a study was conducted with comparing the subjective examination method by using trial and error, while the objective examination was done using streak retinoscopy, It explained the comparison between subjective methods and objective methods in the right and the left eye. To compare the subjective and objective corrections results in the right eye can be done by using diagnostic tests. Sensitivity is the result of correction between subjective and objective, where both are correct at $82.7 \%$. Specificity is the result of correction between subjective and objective, where both are incorrect at $20.0 \%$. Positive predictive value (PPV) is the result of a correction between correct subjective and incorrect objective correction result, which is $91.5 \%$. Negative predictive value (NPV) is the result of correction between incorrect subjective and correct objective correction result, which is $20.0 \%$ and accuracy rate is $77.0 \%$.

In table 10, it shows the comparison between subjective and objective correction results in the left eye by using diagnostic test. Sensitivity is the result of correction between subjective and objective, where both are correct at $98 \%$. Specificity is the result of correction between subjective and objective, where both are incorrect at $25.0 \%$. Positive predictive value (PPV) is the result of a correction between correct subjective and incorrect objective correction result, which is $88,9 \%$. Negative predictive value (NPV) is the result of correction between incorrect subjective and correct objective correction result, which is $66.4 \%$ and accuracy rate is $87.7 \%$.

\section{Conclusion}

1. In this study, the majority of myopia sufferers were male

2. Subjective examination correction results by using Trial and Error and objective examination by using Streak Retinoskop on the right eye, it was obtained that the sensitivity value was $82.7 \%$, with a specificity value was $20.0 \%$, a positive predictive value was $91.5 \%$, a negative predictive value was $20.0 \%$, and an accuracy rate was $77.0 \%$

3. Subjective examination correction results by using Trial and Error and objective examination using Streak Retinoskop on the left eye, it was obtained that the sensitivity level was $98.0 \%$, with a specificity value was $25.0 \%$, a positive predictive value was $88.9 \%$, a negative predictive value was $66.4 \%$ and an accuracy rate was $87.7 \%$

4. In this study, it was found that BCVA had no difference between subjective and objective examination methods on refractive errors.

\section{References}

Ferris JD. 2017. Refractive error. American Academy of ophthalmology

Siregar NH.2008.Retinoskopi. Fakultas Kedokteran Universitas Sumatera Utara: Medan. 2008, p.3-122

Lang GK. 2000. Ophthalmology. Thieme Stuttgar: New York. p.430

Tien Yin Wong.2001. The Ophthalmology examination review. World scientific publishing. Singapore p. 22-25

Hashim. 2012. Prevalence of refractive error in malay primary school children in suburban 
area of kota bahru, Kelantan, Malaysia. Annal of Academy of Medicine

Fricke TR, holden BA, Wilson DA. 2012. Global cost of correcting vision impairment from uncorrected refractive error, pubmed : p; 728-738

Zamilah, A. Prevalensi Kelainan Refraksi di Poliklinik Mata RSUP. H Adam Malik Medan Tahun 2011-2014

Sherwin JC, Lewallen S, Courtright P.2012. FebBlindness and visual impairment due to uncorrected. Br J Ophthalmol. 96(7):927-30 